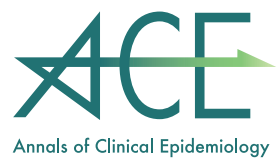

EDITORIAL

\title{
How to review manuscripts
}

\author{
Hideo Yasunaga \\ Editor-in-chief, Annals of Clinical Epidemiology
}

Annals of Clinical Epidemiology (ACE) requires reviewers to provide educational and constructive comments, not to return simple critiques to the authors. Reviewers should attach constructive comments on how to modify the manuscript so that it can be revised to a more attractive version.

This brief paper explains how to review manuscripts; that is, the correct state of mind when reviewing manuscripts.

\section{OBJECTIVE EVALUATION}

Good peer review contributes to the advancement of science. Reviewers should give an objective evaluation for submitted manuscripts.

The general role of reviewers is to evaluate accuracy of the description; validity of methods, results, and discussion; and novelty and originality of the research.

Table 1 shows the key points for objective evaluation of manuscripts.

\section{CONSTRUCTIVE AND EDUCATIONAL COMMENTS}

Reviewers should provide positive feedback that informs the authors how to add or modify the analysis to improve quality of the manuscript. Reviewers' comments that just state their subjective opinions are not constructive, and may only confuse the authors.

It is also non-constructive to force a modification that cannot be handled at all. If reviewers state a strong denial, they should explain the reasons to the author by quoting relevant evidence or data.

Reviewers should provide as many suggestions as possible to aid manuscript revision. These suggestions may include specific examples of plans for correction.

Peer-review of submitted manuscript is different from critical review of published article. Only finding fault with the authors is not recommended. It is almost meaningless for the development of the research area to just nitpick negative feedback to the authors.

Stereotypical comments such as "because the number

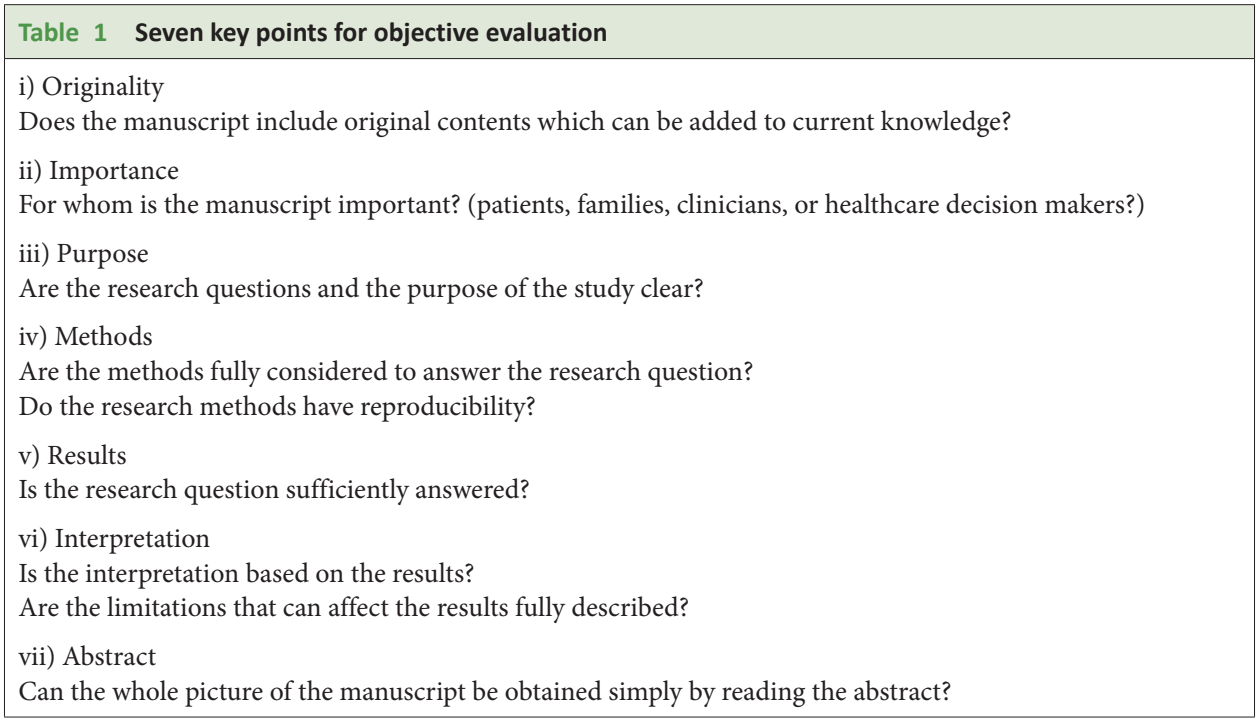


of cases is small" or "because it is not a randomized controlled trial" are far from constructive or educational. All studies have limitations. If the paper has novelty and creativity, some limitation should be allowed.

Reviewers should not point out issues in the secondround peer-review that were not raised in the first-round peer review.

\section{STATE OF MIND WHEN REVIEWING MANUSCRIPTS}

Reviewers should not force their personal style or selftaught manner on the authors. Even if the author's method and consideration are different from their own, reviewers must accept them when scientifically valid.

Reviewers should refrain from impressing their assertion to the author, such as "I am interested in $\mathrm{xx}$, please show relevant data." Forcing their own style often confuses the authors and has the potential to degrade the quality of the paper and thus possibly interfere with the development of the field.

Reviewers should not write comments on things they do not know well. Evaluating with imperfect knowledge has no meaning, which may deteriorate peer-review process.

Reviewers should remain unbiased and neutral at all times. Recommendations on acceptance or rejection should not be affected by the following personal feelings: "Contents of the manuscript match my interests", "The study is similar to my research", "The authors cited my paper", "The author is my acquaintance", "The coauthor is a leading figure in the study area". They should judge from a neutral position.

Many young authors conduct their research, discuss with co-authors, and write manuscripts with enthusiasm and sincerity. Reviewers should avoid aggressive comments that will only show contempt for the author, as it may lead to breaking down the future of the young researcher.

Through peer review, researchers will be trained. Reviewers should be strongly aware of this and maintain their dignity and courtesy.

\section{CONCLUSION}

Most young researchers have poorer skills to write papers than senior investigators. Interaction with good reviewers can be a lifetime property for young researchers. Educational and constructive comments from peer reviewers motivate young researchers to make efforts to modify papers and improve their writings. If appropriate modifications are made and the manuscript is accepted, it will be a great confidence boost for the young researcher and will lead to the next research status. 